OPEN ACCESS

Edited by:

Vincent Vander Poorten, KU Leuven, Belgium

Reviewed by:

Orlando Guntinas-Lichius, University Hospital Jena, Germany Alena Skalova,

Charles University, Czechia

*Correspondence: Steffen Heegaard sthe@sund.ku.dk

Specialty section

This article was submitted to Otorhinolaryngology - Head and Neck Surgery,

a section of the journal

Frontiers in Surgery

Received: 07 July 2020 Accepted: 25 September 2020 Published: 06 November 2020

Citation:

Iversen L, Eriksen PRG, Andreasen S, Clasen-Linde E, Homøe P, Wessel I, von Buchwald $C$ and Heegaard $S$ (2020) Lymphoma of the Sublingual Gland: Clinical, Morphological, Histopathological, and Genetic Characterization.

Front. Surg. 7:581105 doi: 10.3389/fsurg.2020.581105

\section{Lymphoma of the Sublingual Gland: Clinical, Morphological, Histopathological, and Genetic Characterization}

\author{
Lars Iversen ${ }^{1,2}$, Patrick Rene Gerhard Eriksen ${ }^{3}$, Simon Andreasen ${ }^{2,4}$, Erik Clasen-Linde ${ }^{2}$, \\ Preben Homøe ${ }^{4}$, Irene Wessel ${ }^{3}$, Christian von Buchwald ${ }^{3}$ and Steffen Heegaard ${ }^{1,2 *}$ \\ ${ }^{1}$ Department of Ophthalmology, Rigshospitalet-Glostrup, Glostrup, Denmark, ${ }^{2}$ Department of Pathology, Rigshospitalet, \\ Copenhagen, Denmark, ${ }^{3}$ Department of Otorhinolaryngology Head \& Neck Surgery and Audiology, Rigshospitalet, \\ Copenhagen, Denmark, ${ }^{4}$ Department of Otorhinolaryngology and Maxillofacial Surgery, Zealand University Hospital, Køge, \\ Denmark
}

Background: Lymphoma of the sublingual gland is rare, representing $1 \%$ of all salivary gland lymphomas. In this case report, we present three new cases and compare them to previously published cases, with the aim of characterizing the clinical, morphological, histopathological, and genetic features of this type of malignancy.

Materials and Methods: We provide a clinical description of three cases along with a characterization of the microscopic features, including morphology, and immunohistochemistry. In addition, we analysed possible cytogenetic rearrangements with the use of fluorescence in situ hybridization (FISH).

Results: Case 1: A 61-year-old male presenting with a painless swelling of the floor of the mouth diagnosed as extranodal marginal zone lymphoma (EMZL) of the left sublingual gland. The patient is alive with no evidence of disease after his fourth treatment regimen following several relapses. Case 2: A 68-year-old female with a prior history of mantle cell lymphoma (MCL) presenting with a tender swelling of the left sublingual gland as well as the right submandibular gland. The lesions were diagnosed as relapsing $\mathrm{MCL}$. The patient died of unrelated causes after 18 months of treatment. Case 3: A 75-year-old female presenting with a swelling of the floor of the mouth diagnosed as follicular lymphoma (FL) of the left sublingual gland. The patient received chemotherapy along with radiotherapy and was still alive 10 years after the diagnosis.

Conclusion: The three cases of sublingual gland lymphomas presented in this case report resemble lymphomas of other major salivary glands. The clinician should be aware of this type of malignancy and that the clinical presentation may not differ from benign lesions or other more common malignancies in this location.

Keywords: Iymphoma, sublingual glands, salivary glands, extranodal marginal zone lymphoma, mantle cell lymphoma, follicular lymphoma, head and neck 


\section{INTRODUCTION}

Lymphomas are a group of malignancies, which arise from lymphocytes. Usually these are situated in lymphoid tissues but can also be found as an extralymphatic disease. Currently, the World Health Organization Classification recognizes more than 40 different types of lymphoma based on characteristic histology and genetic hallmarks each with a specific locational preference (1). Lymphomas are the third most common malignancy in the head and neck region after squamous cell carcinoma and adenocarcinoma (2), and the major salivary glands are the third most common site for extranodal lymphoma in the head and neck region followed by the ocular adnexa and sinonasal region (3). The Waldeyer's tonsillar ring is also a common site for head and neck lymphomas to arise but in recent literature, this site is not categorized as extranodal. Primary lymphomas of the salivary glands are rare, representing $\sim 1.7-3.1 \%$ of all salivary gland neoplasms. These are distributed with $79 \%$ in the parotid glands, $18 \%$ in the submandibular glands, $2 \%$ in the minor salivary glands, and $1 \%$ in the sublingual glands (4). In the parotid gland, the most frequent types of lymphomas are extranodal marginal zone lymphoma (EMZL), follicular lymphoma (FL), and diffuse large B-cell lymphoma (DLBCL) (5), with EMZL being especially predominant in patients with Sjögren's syndrome (6). The detection of certain chromosomal translocations by fluorescence in situ hybridization (FISH) is used as a diagnostic tool and especially in EMZL genetic rearrangements vary in frequency according to the primary anatomical site of disease establishing a link between genetics and homing of malignant lymphocytes (7). Cytogenetically in salivary gland EMZL, the most common translocations detected are $\mathrm{t}(14 ; 18)(\mathrm{q} 32 ; \mathrm{q} 21)$ IGH/MALT1 and $\mathrm{t}(11 ; 18)(\mathrm{q} 21 ; 21)-A P I 2 / M A L T 1$ (1).

The standard treatment of salivary gland lymphomas includes chemotherapy and/or radiotherapy (RT) depending on the lymphoma subtype. A surgical biopsy of salivary gland lymphomas is performed in order to establish a histological diagnosis. Lymphoma subtype, age of the patient, and stage of the disease, all influence the prognosis of parotid gland lymphomas, with increasing age and stage of disease resulting in a poorer prognosis (5). Additionally, transformation of indolent lymphomas to more aggressive subtypes, usually to DLBCL or high-grade B-cell lymphomas, further decreases the prognosis.

Due to the rarity of sublingual gland lymphomas, little is known about the distribution, presentation, histological subtypes, treatment, and prognosis of this patient group. Here, we present three new cases and characterize their clinical, morphological, histopathological, and genetic profile and compare them to previously published cases.

\section{MATERIALS AND METHODS}

The Danish national pathology data bank (PatoBank) was screened for all cases of lymphomas of the sublingual gland since 1980, resulting in four cases of alleged sublingual gland lymphoma. One case was excluded due to inability to fulfill the diagnostic criteria for lymphoma. Sublingual gland specimens and medical records from the remaining three patients were collected from the respective pathology, hematology and ENTdepartments. If possible, staging was performed using the Cotswolds-modified Ann Arbor classification and the AJCC Lugano classification (8). Primary lymphoma of the sublingual gland is defined as no systemic involvement or involvement of other organs at the time of work-up and no prior history of lymphoma. Secondary lymphoma is defined as concurrent systemic disease or involvement of other organs at the time of work-up and/or prior history of lymphoma.

\section{Validation of Diagnoses}

Formalin-fixed and paraffin-embedded (FFPE) tissue from the three sublingual gland lymphomas were cut and stained with haematoxylin and eosin (HE), periodic acid-Schiff (PAS), and Alcian blue. Immunohistochemistry was performed on a Ventana Benchmark Ultra platform (Ventana Medical Systems, Tucson, AZ, USA) as previously described (9). The following antibodies were applied: CD3, CD5, CD10, CD20, CD23, CD79 $\alpha$, cyclin D-1, BCL2, BCL6, MUM-1/IRF4, PAX5, SOX11, Ki 67, and $\kappa$ and $\lambda$ light chains. Positive and negative controls were included on each slide.

FISH was performed using the break-apart probes for $\mathrm{Bcl}$ 2, Bcl-6, C-MYC, and specific probes for IGH/MALT1 and IGH/CCND1 rearrangements, according to the manufacturers' protocol using the HYBrite platform (Abbott Molecular). After hybridization nuclei were counterstained with DAPI II (ZytoVision). One hundred nuclei were counted, and only nuclei where the entire nuclear membrane could be visualized were scored. Cut-off value was defined as $10 \%$. Examination of the slides and validation of the diagnoses were performed by a specialized hematopathologist.

\section{Ethics}

The study was approved by the local scientific ethics committee (Journal no. H-16023080) and the Danish Data Protection Agency (Journal no. P-2020-587). Written informed consent was obtained from the individuals for the publication of any potentially identifiable images or data included in this article.

\section{RESULTS}

\section{Case 1}

A 61-year-old male was seen in the ENT-department as an outpatient with a 1-month history of a painless swelling of the floor of the mouth. Previous medical history was unremarkable except for a Warthin's tumor of the parotid gland and prostate hypertrophy. Clinical examination revealed a two-centimeter mobile process in the left sublingual area (Table 1) and no enlarged lymph nodes in the head and neck region. The process was surgically excised in local anesthesia. Subsequent histological examination showed a well-defined tumor infiltrating salivary gland tissue with resulting destruction of the acinar architecture. Tumor tissue was composed of small homogeneous lymphoid cells with irregular nuclei and plasmacytic cell-differentiation among scattered ductal structures (Figure 1C). Immunohistochemically, case 1 showed positive reaction on the tumor cells' surface for Bcl-2 and $\mathrm{CD} 20$, and the 
TABLE 1 | Demographic, clinical presentation, subtype, stage, treatment, and outcome of previously published sublingual gland lymphomas.

\begin{tabular}{|c|c|c|c|c|c|c|c|}
\hline Study & Age/sex/laterality & Clinical presentation & Subtype & Stage AA/AJCC & $\mathrm{P} / \mathrm{S}$ & Treatment & Clinical course \\
\hline Takahashi et al. (12) & $67 / \mathrm{M} / \mathrm{R}$ & Swelling & EMZL & NA & $\mathrm{P}$ & Surgery + RT + chemotherapy (NS) & $D, 3$ yrs \\
\hline Honda et al. (14) & 71/F/B & $\begin{array}{l}\text { Hard, elastic, mobile } \\
\text { swelling }\end{array}$ & EMZL & NA & NA & $\mathrm{RT}$ & NA \\
\hline Honda et al. (14) & 63/F/R & $\begin{array}{l}\text { Hard, elastic, mobile } \\
\text { swelling }\end{array}$ & EMZL & NA & NA & Surgery & NA \\
\hline Honda et al. (14) & 82/F/L & $\begin{array}{l}\text { Hard, elastic, mobile } \\
\text { swelling }\end{array}$ & EMZL & NA & NA & Chemotherapy (NS) & $\mathrm{D}, 2 \mathrm{yrs}$ \\
\hline Yoshiba et al. (11) & 64/M/L & $\begin{array}{l}\text { Diffuse, firm, painless } \\
\text { swelling }\end{array}$ & EMZL & $\mathrm{I} / \mathrm{IE}$ & $P$ & Surgery & NED, 36 mo \\
\hline Makihara et al. (19) & $81 / \mathrm{M} / \mathrm{R}$ & $\begin{array}{l}\text { Fibrous, painless } \\
\text { swelling }\end{array}$ & EMZL & $\mathrm{I} / \mathrm{IE}$ & $\mathrm{P}$ & Surgery & NED, NA \\
\hline Present case 1 & $61 / \mathrm{M} / \mathrm{L}$ & $\begin{array}{l}\text { Painless, mobile } \\
\text { swelling }\end{array}$ & EMZL & IVA/IV & $S$ & Surgery + chlorambucil + RT & NED, 16 yrs \\
\hline Rockacy et al. (16) & 72/F/R & $\begin{array}{l}\text { Painless swelling, } \\
\text { normal overlying } \\
\text { mucosa }\end{array}$ & $\mathrm{MCL}$ & IVA/IV & $S$ & Surgery + observation & A, 1 yr \\
\hline Hayashi et al. (15) & 82/M/B & $\begin{array}{l}\text { Elastic, hard, painless } \\
\text { swelling }\end{array}$ & $\mathrm{MCL}$ & IV/IV & $S$ & $\mathrm{RT}+$ rituximab & D, 3 yrs \\
\hline Abukrian et al. (13) & 70/M/B & Swelling & $\mathrm{MCL}$ & IV/IV & S & Rituximab-bendamustine & NED, $11 \mathrm{mo}$ \\
\hline Present case 2 & 70/F/L & $\begin{array}{l}\text { Tender swelling, normal } \\
\text { overlying mucosa }\end{array}$ & $\mathrm{MCL}$ & IVB/IV & $S$ & Surgery + ibrutinib & DOC, $40 \mathrm{mo}$ \\
\hline Law and Leader (10) & 58/F/R & Painless swelling & $\mathrm{FL}$ & $\mathrm{IV} / \mathrm{IV}$ & S & Surgery + chlorambucil & NA \\
\hline Williams et al. (18) & 74/F/L & $\begin{array}{l}\text { Firm, tender swelling, } \\
\text { ulcerated mucosa }\end{array}$ & $\mathrm{FL}$ & IIIEA/IV & $S$ & Surgery & NA \\
\hline Present case 3 & 75/F/L & $\begin{array}{l}\text { Mobile swelling, no } \\
\text { redness, or wounds }\end{array}$ & FL & IA/IE & $P$ & Surgery + CHOP + RT & NED, 10 yrs \\
\hline Gleeson et al. (20) & NA & NA & $\mathrm{SLL}^{*}$ & $\mathrm{I} / \mathrm{IE}$ & $P$ & Surgery & $\mathrm{A}, 34 \mathrm{mo}$ \\
\hline Schwartz-Arad et al. (17) & 72/M/R & Asymptomatic swelling & $\mathrm{LL}^{\dagger}$ & NA & NA & Surgery + RT & $\mathrm{A}, 6 \mathrm{mo}$ \\
\hline León et al. (21) & 44/M/NA & NA & DLBCL & NA & NA & NA & $\mathrm{D}, \mathrm{NA}$ \\
\hline
\end{tabular}

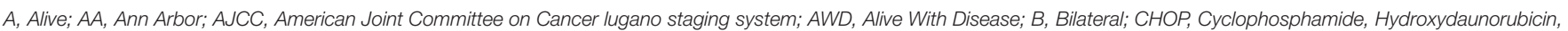

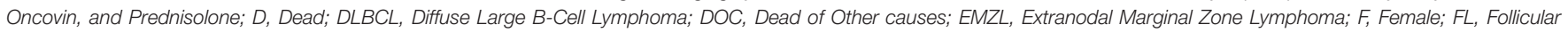

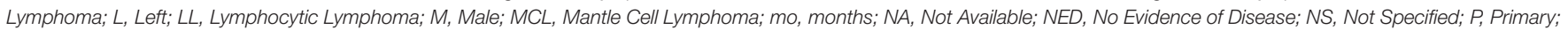
R, Right; RT, Radio Therapy; S, Secondary; SLL, Small Lymphocytic Lymphoma; yrs, years.

*leukemic infiltration.

${ }^{\dagger}$ not otherwise specified.

proliferation marker Ki67 showed a proliferation index estimated to $20 \%$. Furthermore, both lymphocytes and plasma cells showed lambda light chain restriction (Figure 1D). Finally, FISH was performed showing an IGH/MALT1 translocation (16\% of the cells showing a signal), consistent with a diagnosis of EMZL of the sublingual gland. Subsequent bone marrow biopsy revealed lymphoma involvement and computed tomography (CT) did not show involvement of other sites. Accordingly, the lymphoma was Ann Arbor stage IVA and AJCC stage IV. The patient received chlorambucil for 1 year until complete remission. Three years later, the patient presented with a 2-month history of dry cough, night sweats, and an involuntary weight loss of 3$5 \mathrm{~kg}$. CT scan revealed processes in the lungs, mediastinal-, and inguinal lymph nodes. Core needle biopsy from the right lung confirmed relapse of the EMZL. The patient received 8 series of rituximab, cyclophosphamide, vincristine, and prednisolone (R-CVP) until complete remission, with only one marginally enlarged lymph node remaining near the aorta, followed by a 2-year-period of maintenance therapy with rituximab. Three years later, the patient relapsed presenting with a subfascial tumor below the left infraorbital margin, resulting in three series of rituximab and bendamustine followed by RT (24 Gy in 12 fractions) until complete remission. Five years later, the patient again presented with night sweats and fatigue. Positron emission tomography (PET)-CT scan revealed multiple pathological lymph nodes above and below the diaphragm, and biopsies confirmed relapse of the EMZL with transformation to DLBCL. The patient received five series of rituximab, cyclophosphamide, hydroxydaunorubicin, oncovin, and prednisolone (R-CHOP) and subsequent PET-CT showed complete remission. The patient is currently scheduled for regular follow-up examination with diagnostic imaging and clinical visits.

\section{Case 2}

A 68-year-old female was referred from an ENT specialist practitioner to the ENT-department due to multiple enlarged cervical lymph nodes located bilaterally and an involuntary weight loss of 10 kilograms over the last 6 months. There was 

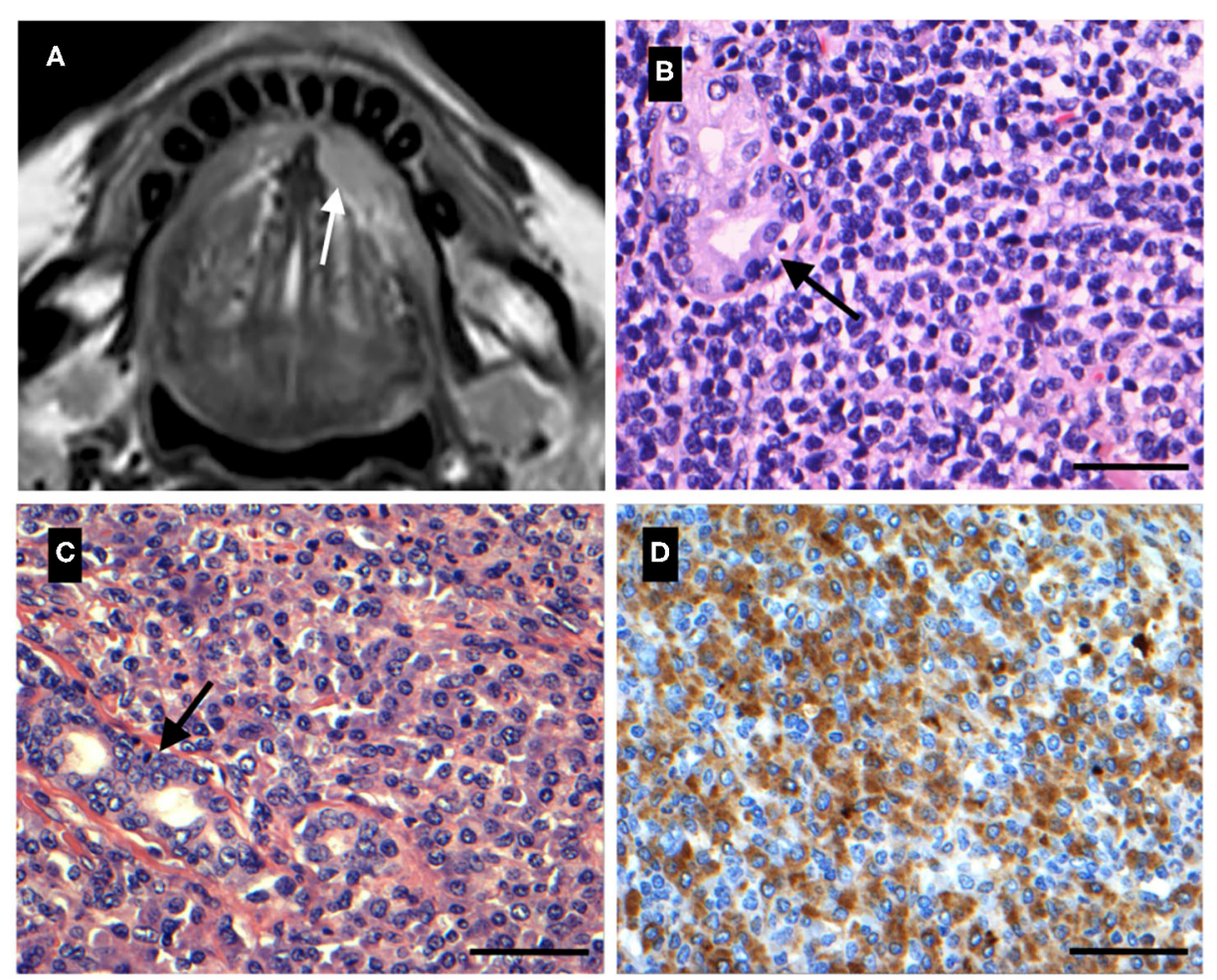

FIGURE 1 | (A) A 68-year-old female with relapse of known Mantle cell lymphoma (MCL) resulting in swelling of the left sublingual gland. Magnetic resonance imaging (MRI) showing a tumor of the left sublingual gland (white arrow). (B) Histological image of the sublingual gland MCL (A). Salivary gland tissue is infiltrated by lymphoid tumor tissue and small tumor cells are seen with multiple membrane bound nucleoli. Ductal structures are seen (black arrow) (HE). (C) A 61-year-old male with 1-month history of painless swelling of the floor of the mouth. Tumor tissue was composed of neoplastic lymphoid cells with irregular nuclei and plasmacytic differentiation, consistent with a diagnosis of extranodal marginal zone lymphoma (EMZL) of the left sublingual gland. Scattered ductal structures are seen (black arrow) (HE). (D) Immunohistochemistry of the sublingual gland EMZL (C) showing positive reaction for lambda light chain. Scale bar $=50 \mu \mathrm{m}$.

no significant previous medical history. Fine needle aspiration biopsy (FNAB) suggested lymphoma and subsequent histological examination of an excised lymph node between level two and three from the left side of the neck confirmed the diagnosis of mantle cell lymphoma (MCL). PET-CT and bone marrow examination further demonstrated bone marrow involvement. Accordingly, the lymphoma was staged as Ann Arbor IVB and AJCC stage IV. The patient received eight series of R-CHOP followed by a scheduled 2-year-period of maintenance therapy with rituximab. Twelve months into maintenance therapy the patient developed a tender swelling of the right submandibularand left sublingual gland. On clinical examination, a onecentimeter process with normal overlying mucosa was found in the left sublingual gland (Table 1) along with a similar process in the right submandibular gland. Ultrasound of the left sublingualand right submandibular gland revealed two hyperechoic onecentimeter tumors. Further examination and ultrasound of the neck revealed no enlarged lymph nodes. A magnetic resonance imaging (MRI) of the head and neck was performed (Figure 1A). PET-CT revealed a process of the sigmoid colon, but the bone marrow examination showed no signs of infiltration. MCL relapse was confirmed by subsequent excision and histological examination of the sublingual- and submandibular gland, as well as histological examination of a biopsy specimen taken from the sigmoid colon via colonoscopy. Histological examination of the excised sublingual gland showed salivary gland tissue infiltrated by lymphoid tumor cells appearing as blastoid cells with multiple membrane bound nucleoli (Figure 1B). Mitotic figures were seen in several of these cells. Immunohistochemistry showed positive reaction in the tumor cells' nuclei for PAX5, cyclin D1, and SOX11 and on the tumor cells' surface for CD5 and the proliferation index was estimated to $>80 \%$. Furthermore, flow cytometry detected $70.1 \%$ clonal B-cells positive for CD5, CD10, CD19, CD20, CD43, and CD79 and with lambda light chain restriction. FISH demonstrated an IGH/CCND1 translocation (65\% of the cells showing a signal), consistent with a diagnosis of MCL. Ibrutinib was initiated but the patient died 18 month later due to advancing heart failure and declining performance status.

\section{Case 3}

A 75-year-old female was referred from an ENT specialist practitioner to the ENT-department due to a swelling of the floor of the mouth. Previous medical history was unremarkable. Clinical examination revealed a 1.5 -centimeter mobile process at the left caruncle covered by intact mucosa (Table 1) and no enlarged lymph nodes in the head and neck region. FNAB of the 
lesion was inconclusive, thus the lesion was surgically excised in general anesthesia. Subsequent histological examination showed tumor tissue infiltrating closely packed salivary gland tissue. The tumor tissue was composed of lymphoid cells extending in a follicular growth pattern, consisting of a mixture of mediumsized irregularly shaped cells with indented nuclei and larger blastoid cells with multiple nucleoli. Approximately 15-20\% of the tumor cells were centroblasts. Immunohistochemistry showed positive reaction on the tumor cells' surface for CD10, CD20, and Bcl-2 and in the tumor cells' nuclei for Bcl-6 and a proliferation index of $20 \%$. Accordingly, case 3 was diagnosed as a grade II FL. Subsequent CT scan and bone marrow examination showed no signs of further dissemination of the disease and the lymphoma was classified as Ann Arbor stage IA and AJCC stage IE. Treatment included three series of CHOP followed by RT (26 Gy in 13 fractions). The patient went into full remission with no evidence of disease 10 years after the diagnosis, and the patient is still alive.

\section{DISCUSSION}

In this case report our research group presents three rare cases of sublingual gland lymphomas, significantly contributing to the number of cases reported worldwide. Table 1 provides an overview of demographic, clinical presentation, subtype, stage, treatment, and outcome of the present three cases along with previously published sublingual gland lymphomas (10-21). Overall, the most common clinical presentation was a painless swelling of the floor of the mouth with no signs of affected overlying mucosa (Table 1). Other salivary gland tumors may have a similar clinical presentation, and thus, there are no clear clinical distinguishable signs between benign lesions (e.g., pleomorphic adenomas) or malignant lesions (e.g., carcinomas, adenocarcinomas) of the sublingual gland and sublingual gland lymphomas. This has also been reported to be the case in parotid gland lymphomas (22). Sublingual gland lymphomas presenting as painful were more uncommon, with one MCL being reported as tender and one FL presenting as a tender swelling covered by ulcerated mucosa (Table 1). Differential diagnoses to painful swellings of the salivary glands include swelling caused by sialolithiasis or sialadenitis.

Including present and previous cases of sublingual gland lymphomas (Table 1), the most frequent histological subtype encountered was EMZL (41.2\%), followed by MCL (23.5\%), and FL (17.6\%). This distribution is similar to the distribution in the parotid and lacrimal gland, with EMZL being the most frequent lymphoma subtype in these locations as well, accounting for 27.9 and $37 \%$, respectively $(5,23)$. The primary genetic event in MCL is the $\mathrm{t}(11 ; 14)(\mathrm{q} 13 ; \mathrm{q} 32)$ translocation between an $I G H$ gene and the gene encoding cyclin D1 (CCND1). This gene rearrangement is seen in more than $95 \%$ of the cases, and thus serves as an important information in the diagnostic work-up of MCL. In contrast, multiple chromosomal translocations are associated with EMZL with frequencies of the translocations depending on the anatomical site. The $\mathrm{t}(14 ; 18)(\mathrm{q} 32 ; 21) / I G H$ $M A L T 1$ translocation is most commonly seen in salivary gland, ocular adnexa, and orbital EMZL (1), which shows that a genetic disposition in the lymphocytes lead to specific homing to and colonization of certain tissues (7). A feared complication to indolent lymphomas such as EMZL and FL is the risk of transformation to a more aggressive subtype, most commonly DLBCL or high-grade B-cell lymphoma characterized by a MYC and $B c l-2$ and/or Bcl-6 translocation (so called double/triple hit lymphoma) and poor prognosis (24).

In general, RT is the treatment of choice for low stage indolent extranodal lymphomas, such as EMZL and FL, with the role of surgery largely being limited to diagnostic purposes. Systemic chemotherapy is indicated for more aggressive or advanced staged extranodal lymphomas, with RT primarily being used as adjuvant or palliative therapy (25). For asymptomatic patients with early stage FL, a watch and wait strategy is a widely accepted approach in regards to the initial management of the disease (26), though, $\sim 2-3 \%$ per year of all follicular lymphomas transform to a more aggressive subtype (27). While single therapy RT is an accepted treatment for FL, newer studies suggest that the addition of rituximab to RT could further improve outcome in patients with early stage FL $(28,29)$. RT is also considered as a standard therapy for early stage EMZL, generally with a good prognosis (30). With more advanced staged EMZL, R-bendamustine has been proven to be both an effective and well-tolerated therapy regimen (31). In the case of advanced staged MCL, especially regarding elderly patients, who are not eligible for autologous stem-cell transplantation, chemotherapy is the treatment of choice. In these situations R-CHOP followed by rituximab maintenance therapy is a possible treatment regimen (32).

Stage and clinical course of previously published cases of sublingual gland lymphomas were not fully available, making it difficult to describe the prognosis of lymphomas located to this location (Table 1). Prior studies on lymphomas of other major salivary glands found that age, stage of disease, treatment, and lymphoma subtype influenced the prognosis, with EMZL being among the subtypes with the highest overall survival (OS) (5). In a recent study, 248 patients with EMZL of the parotid and submandibular glands were analyzed, and a median OS of 18.3 years and a progression-free survival (PFS) of 9.3 years were found (33). Marginal zone lymphomas of other extranodal sites have also been proven to have a favorable outcome, with reports of a 5 -year OS of 75\% for EMZL of the lacrimal gland (23). On the contrary, transformation of indolent lymphomas to more aggressive subtypes may result in an unfavorable prognosis. A PFS of 14 months and an OS of 42 months have been reported for indolent lymphomas undergoing secondary transformation after a preceding diagnosis (34).

In conclusion, we present three cases of sublingual gland lymphoma and characterize their clinical, morphological, histopathological, and genetic profile and compare them to previously published cases. The most common lymphoma subtype in this location is EMZL, but both MCL and FL has been reported as well. This is similar to the distribution found in the lacrimal gland and other major salivary glands, where EMZL is the dominating subtype as well. Clinical presentation of sublingual gland lymphomas may also resemble that of lymphomas located to other major salivary glands. In the 
assessment of a painless swelling of the sublingual gland, lymphoma should be considered as a differential diagnosis to gland inflammation, benign lesions, and other more common malignancies in this location such as carcinomas and adenocarcinomas, especially in patients with prior history of lymphoma or leukemia. The condition of the patient, along with the stage and subtype of the lymphoma, should be taken into consideration when choosing a treatment regimen. Outcome of the present three cases was not uniform but reflected the stage and subtype of the lymphoma. The limited number of cases included in this study makes it difficult to draw certain conclusions on the prognosis of sublingual gland lymphomas. In the future, further cases should be presented so to establish valid prognoses, progression rates, and treatment efficacy for lymphomas in this location.

\section{DATA AVAILABILITY STATEMENT}

All datasets generated for this study are included in the article/supplementary material.

\section{REFERENCES}

1. Swerdlow SH, Campo E, Harris NL, Jaffe ES, Pileri SA, Stein H, et al. WHO Classification of Tumours of Haematopoetic and Lymphoid Tissues. 4th ed. Lyon: IARC (2008).

2. Cooper JS, Porter K, Mallin K, Hoffman HT, Weber RS, Ang KK, et al. national cancer database report on cancer of the head and neck: 10-year update. Head Neck. (2009) 31:748-58. doi: 10.1002/hed.21022

3. Weber AL, Rahemtullah A, Ferry JA. Hodgkin and nonHodgkin lymphoma of the head and neck: clinical, pathologic, and imaging evaluation. Neuroimaging Clin $N$ Am. (2003) 13:371-92. doi: 10.1016/S1052-5149(03)00039-X

4. Barnes L, Myers EN, Prokopakis EP. Primary malignant lymphoma of the parotid gland. Arch Otolaryngol Head Neck Surg. (1998) 124:5737. doi: 10.1001/archotol.124.5.573

5. Feinstein AJ, Ciarleglio MM, Cong X, Otremba MD, Judson BL. Parotid gland lymphoma: prognostic analysis of 2140 patients. Laryngoscope. (2013) 123:1199-203. doi: 10.1002/lary.23901

6. Retamozo S, Brito-Zerón P, Ramos-Casals M. Prognostic markers of lymphoma development in primary Sjögren syndrome. Lupus. (2019) 28:92336. doi: 10.1177/0961203319857132

7. Pals ST, De Gorter DJJ, Spaargaren M. Lymphoma dissemination: The other face of lymphocyte homing. Blood. (2007) 110:310211. doi: 10.1182/blood-2007-05-075176

8. Amin MB, Edge S, Greene F, Byrd DR, Brookland RK, Washington MK, et al. AJCC Cancer Staging Manual. 8th ed. Springer International Puplishing; American Joint Commission on Cancer (2017).

9. Andreasen S, Therkildsen MH, Grauslund M, Friis-Hansen L, Wessel I, Homøe P. Activation of the interleukin-6/Janus kinase/STAT3 pathway in pleomorphic adenoma of the parotid gland. Apmis. (2015) 123:70615. doi: 10.1111/apm.12407

10. Law NW, Leader M. Bilateral submandibular gland lymphoma in Sjogren's syndrome. Postgrad Med J. (1987) 63:135-6. doi: 10.1136/pgmj.63.7 36.135

11. Yoshiba S, Kamatani T, Kondo S, Shintani S. Primary sublingual gland marginal zone B cell lymphoma of mucosa-associated lymphoid tissue type: a case report. Asian J Oral Maxillofac Surg. (2011) 23:2013. doi: 10.1016/j.ajoms.2011.04.004

12. Takahashi H, Cheng J, Fujita S, Tsuda N, Tezuka F, Liu AR, et al. Primary malignant lymphoma of the salivary gland: a tumor of

\section{ETHICS STATEMENT}

The study was approved by the local scientific ethics committee (Journal no. H-16023080) and the Danish Data Protection Agency (Journal no. P-2020-587). Written informed consent was obtained from the individuals for the publication of any potentially identifiable images or data included in this article.

\section{AUTHOR CONTRIBUTIONS}

EC-L: validation of histological diagnoses. SA and PE: analysis of FISH. LI: first draft. All authors conception and design, critical revision for intellectual content, and approval of the final version and accountable for all aspects of the work.

\section{ACKNOWLEDGMENTS}

This work was supported by Candys Foundation (ref. no. 2019-333).

mucosa-associated lymphoid tissue. J Oral Pathol Med. (1992) 21:31825. doi: 10.1111/j.1600-0714.1992.tb01019.x

13. Abukrian I, Jasser J, Hoffman HT, Syrbu S. Mantle cell lymphoma involving major and minor salivary glands with parotid sparing. JAMA Otolaryngol. (2020) 146:309-11. doi: 10.1001/jamaoto.2019.4116

14. Honda K, Kusama H, Takagi S, Sekine S, Noguchi M, Chiba H. Diagnosis of intra-oral MALT lymphoma using seminested polymerase chain reaction. $\mathrm{Br}$ J Oral Maxillofac Surg. (2004) 42:28-32. doi: 10.1016/S0266-4356(03)00233-X

15. Hayashi Y, Moriyama M, Maehara T, Goto Y, Kawano S, Ohta M, et al. A case of mantle cell lymphoma presenting as IgG4-related dacryoadenitis and sialoadenitis, so-called mikulicz's disease. World J Surg Oncol. (2015) 13:1-5. doi: 10.1186/s12957-015-0644-0

16. Rockacy J, Viozzi CF, Zent CS. Mantle cell lymphoma presenting as a slowly enlarging lesion of the floor of mouth in a healthy 72-yearold female: report of a case. J Oral Maxillofac Surg. (2007) 65:3337. doi: 10.1016/j.joms.2005.06.024

17. Schwartz-Arad D, Azaz B, Shteyer A. Malignant lymphoma arising in the submandibular and sublingual salivary glands: report of cases. J Oral Maxillofac Surg. (1987) 45:795-9. doi: 10.1016/0278-2391(87)90206-0

18. Williams TP, Vincent SD, Connor FA. A mass in the floor of the mouth. J Oral Maxillofac Surg. (1993) 51:1385-8. doi: 10.1016/S0278-2391(10)80146-6

19. Makihara H, Goto M, Watanabe H, Fukuta K, Otsuka A, Kubo K, et al. Primary mucosa-associated lymphoid tissue lymphoma of the sublingual gland: a case report. J Oral Maxillofac Surg. (2014) 72:e1645. doi: 10.1016/j.joms.2014.06.297

20. Gleeson MJ, Bennett MH, Cawson RA. Lymphomas of salivary glands. Cancer. (1986) 58:699-704. doi: 10.1002/1097-0142(19860801)58:3<699::AIDCNCR2820580317>3.0.CO;2-E

21. León JE, Mauad T, Saldiva PHN, Almeida OP, Vargas PA. Submandibular and sublingual glands involvement in advanced acquired immunodeficiency syndrome (AIDS): an autopsy-based study. Oral Surgery, Oral Med Oral Pathol Oral Radiol Endodontol. (2009) 108:216-26. doi: 10.1016/j.tripleo.2009.03.007

22. Shum JW, Emmerling M, Lubek JE, Ord RA. Parotid lymphoma: a review of clinical presentation and management. Oral Surg Oral Med Oral Pathol Oral Radiol. (2014) 118:1-5. doi: 10.1016/j.oooo.2013.10.013

23. Rasmussen P, Ralfkiaer E, Prause JU, Sjö LD, Siersma VD, Heegaard S. Malignant lymphoma of the lacrimal gland: a nation-based study. Arch Ophthalmol. (2011) 129:1275-80. doi: 10.1001/archophthalmol. 2011.270 
24. Godfrey J, Leukam MJ, Smith SM. An update in treating transformed lymphoma. Best Pract Res Clin Haematol. (2018) 31:251-61. doi: 10.1016/j.beha.2018.07.008

25. Yahalom J, Illidge T, Specht L, Hoppe RT, Li YX, Tsang R, et al. Modern radiation therapy for extranodal lymphomas: field and dose guidelines from the international lymphoma radiation oncology group. Int J Radiat Oncol Biol Phys. (2015) 92:11-31. doi: 10.1016/j.ijrobp.2015.01.009

26. Advani R, Rosenberg SA, Horning SJ. Stage I and II follicular non-Hodgkin's lymphoma: long-term follow-up of no initial therapy. J Clin Oncol. (2004) 22:1454-9. doi: 10.1200/JCO.2004.10.086

27. Link BK, Maurer MJ, Nowakowski GS, Ansell SM, MacOn WR, Syrbu SI, et al. Rates and outcomes of follicular lymphoma transformation in the immunochemotherapy era: a report from the university of Iowa/mayo clinic specialized program of research excellence molecular epidemiology resource. J Clin Oncol. (2013) 31:3272-8. doi: 10.1200/JCO.2012.48.3990

28. Janikova A, Bortlicek Z, Campr V, Kopalova N, Benesova K, Belada $\mathrm{D}$, et al. Radiotherapy with rituximab may be better than radiotherapy alone in first-line treatment of early-stage follicular lymphoma: is it time to change the standard strategy? Leuk Lymphoma. (2015) 56:23506. doi: 10.3109/10428194.2014.990010

29. Ruella M, Filippi AR, Bruna R, Di Russo A, Magni M, Caracciolo D, et al. Addition of rituximab to involved-field radiation therapy prolongs progression-free survival in stage I-II follicular lymphoma: results of a multicenter study. Int J Radiat Oncol Biol Phys. (2016) 94:78391. doi: 10.1016/j.ijrobp.2015.12.019

30. Teckie S, Qi S, Lovie S, Navarrett S, Hsu M, Noy A, et al. Long-term outcomes and patterns of relapse of early-stage extranodal marginal zone lymphoma treated with radiation therapy with curative intent. Int J Radiat Oncol Biol Phys. (2015) 92:130-7. doi: 10.1016/j.ijrobp.2015.01.040
31. Salar A, Domingo-Domenech E, Panizo C, Nicolás C, Bargay J, Muntañola $\mathrm{A}$, et al. First-line response-adapted treatment with the combination of bendamustine and rituximab in patients with mucosaassociated lymphoid tissue lymphoma (MALT2008-01): a multicentre, single-arm, phase 2 trial. Lancet Haematol. (2014) 1:e104-11. doi: 10.1016/S2352-3026(14)00 021-0

32. Kluin-Nelemans HC, Hoster E, Hermine O, Walewski J, Trneny M, Geisler $\mathrm{CH}$, et al. Treatment of older patients with mantle-cell lymphoma. $\mathrm{N} \mathrm{Engl} \mathrm{J}$ Med. (2012) 367:520-31. doi: 10.1056/NEJMoa1200920

33. Jackson AE, Mian M, Kalpadakis C, Pangalis GA, Stathis A, Porro E, et al. Extranodal marginal zone lymphoma of mucosa-associated lymphoid tissue of the salivary glands: a multicenter, international experience of 248 patients (IELSG 41). Oncologist. (2015) 20:114953. doi: 10.1634/theoncologist.2015-0180

34. Demirdas S, Hense J, Dührsen U, Hüttmann A. Treatment outcome in patients with primary or secondary transformed indolent B-Cell lymphomas. Oncol Res Treat. (2019) 42:580-8. doi: 10.1159/000502754

Conflict of Interest: The authors declare that the research was conducted in the absence of any commercial or financial relationships that could be construed as a potential conflict of interest.

Copyright (c) 2020 Iversen, Eriksen, Andreasen, Clasen-Linde, Homøe, Wessel, von Buchwald and Heegaard. This is an open-access article distributed under the terms of the Creative Commons Attribution License (CC BY). The use, distribution or reproduction in other forums is permitted, provided the original author(s) and the copyright owner(s) are credited and that the original publication in this journal is cited, in accordance with accepted academic practice. No use, distribution or reproduction is permitted which does not comply with these terms. 